\title{
Synthesis and Spectral Properties of Low-Symmetry Phenoxy(chloro) and Phenylsulfanyl(chloro) Substituted Phthalocyanines
}

\author{
Andrey I. Koptyaev, Nikolay E. Galanin, ${ }^{\circledR}$ and Gennady P. Shaposhnikov \\ Ivanovo State University of Chemistry and Technology, 153000 Ivanovo, Russia \\ @Corresponding authorE-mail: nik-galanin@yandex.ru
}

\begin{abstract}
Low-symmetry phthalocyanines of the $A_{3} B, A A B B$ and $A B A B$ types were synthesized by mixed condensation of 4,5diphenoxyphthalonitrile or 4,5-bis(phenylsulfanyl)phthalonitrile (components A) with tetrachlorophthalonitrile (component B). The compounds are isolated and purified by column chromatography. The composition and structure of the phthalocyanines were confirmed by elemental analysis, mass spectrometry, NMR and UV-Vis spectroscopy. On the basis of the UV-Vis and NMR spectroscopic data, strong aggregation of these compounds in solutions of polar and non-polar solvents was demonstrated.
\end{abstract}

Keywords: Low-symmetry phthalocyanines, synthesis, spectral properties.

\section{Синтез и спектральные свойства низкосимметричных фенокси(хлор) - и фенилсульфанил(хлор)замещенных фталоцианинов}

\author{
А. И. Коптяев, Н. Е. Галанин, ${ }^{\circledR}$ Г. П. Шапошников \\ ФГБОУ ВПО Ивановский государственный химико-технологический университет, НИИ МГЦС, 153000 Иваново, \\ Россия \\ ${ }^{\circledR}$ E-mail: nik-galanin@yandex.ru
}

Смешанной конденсащией 4,5-дифеноксифталонитрила или 4,5-бис(фенилсульфанил)фталонитрила (компоненты A) с тетрахлорфталонитрилом (компонент В) синтезированы низкосимметричные фтталоцианины типов $A_{3} B, A A B B$ и $А В A B$ и исследованы их спектральные свойства.

Ключевые слова: Низкосимметричные фталоцианины, синтез, спектральные свойства.

\section{Introduction}

Low-symmetry phthalocyanines that concurrently bear strong electron donating and electron withdrawing substituents have a wide range of potential applications. These compounds possess substantive dipole moments and can be used in the fields of optics, ${ }^{[1-3]}$ nanotechnology, ${ }_{,}^{[4]}$ and harvesting of solar energy. ${ }^{[5]}$ Enhanced solubility in organic solvents is an important requirement for low-symmetry phthalocyanines as it facilitates their isolation, identification and extends their application areas. Introduction of aryloxyand arylsulfonyl groups is often employed to increase the solubility of phthalocyanines. ${ }^{[6,7]}$

The current communication describes synthesis and spectral study of low-symmetry phthalocyanines bearing phenoxyl or phenylsulfanyl substituents and chlorine atoms. 


\section{Experimental}

The electronic absorption spectra of the synthesized compounds (working concentrations $\sim 5 \cdot 10^{-6} \mathrm{~mol} / \mathrm{L}$ ) were recorded in chemically pure grade benzene on a Helios Zeta spectrophotometer, the IR spectra in the range of $400-4000 \mathrm{~cm}^{-1}$ were recorded on an Avatar 360 FT-IR spectrophotometer using thin films, the ${ }^{1} \mathrm{H}$ NMR spectra were obtained on a Bruker Avance-500 instrument in $\mathrm{CDCl}_{3}$ (signal of the residual protons of the deuterated solvent at 7.28 ppm was used as reference), the mass spectra (MALDI-TOF using $\alpha$-cyano-4-hydroxycinnamic acid matrix) were obtained on a Bruker Reflex III mass-spectrometer. Elemental analysis was performed on a FlashEA 1112 CHNS-O Analyzer.

4,5-Dichlorophthalonitrile (99\%), tetrachlorophthalonitrile (98 \%) and thiophenol (97\%) were purchased in Sigma-Aldrich and used as received. The chemically pure grade solvents used in the current research were purchased from Ekos-1 ltd.

4,5-Diphenoxyphthalonitrile (1) and 4,5-bis(phenylsulfanyl) phthalonitrile (2). General procedure. A mixture of $1.0 \mathrm{~g}(5.1 \mathrm{mmol})$ 4,5-dichlorophthalonitrile, $1.4 \mathrm{~g}(15.3 \mathrm{mmol})$ phenol or $1.7 \mathrm{~g}(15.3$ mmol) thiophenol, $3.0 \mathrm{~g}(22 \mathrm{mmol}) \mathrm{K}_{2} \mathrm{CO}_{3}$ and $30 \mathrm{ml}$ of anhydrous hexan-1-ol was stirred at $110{ }^{\circ} \mathrm{C}$ for $8 \mathrm{~h}$, then cooled and diluted with $100 \mathrm{ml}$ of water. The precipitate formed was filtered, washed successively with $5 \% \mathrm{KOH}$ and water to $\mathrm{pH} 7$ and dried at $70{ }^{\circ} \mathrm{C}$.

4,5-Diphenoxyphthalonitrile (1). Yield: $1.3 \mathrm{~g}(85 \%)$ as a grayish powder soluble in acetone, chloroform, DMF and DMSO. IR $v \mathrm{~cm}^{-1}: 2226(\mathrm{C} \equiv \mathrm{N}), 1248(\mathrm{C}-\mathrm{O}-\mathrm{C}) .{ }^{1} \mathrm{H} N M R \delta_{\mathrm{H}}$ ppm: 7.50-7.47 $\mathrm{t}(4 \mathrm{H}, J=8 \mathrm{~Hz}), 7.33-7.30 \mathrm{t}(2 \mathrm{H}, J=7 \mathrm{~Hz}), 7.19 \mathrm{~s}(2 \mathrm{H}), 7.12-7.10$ d $(4 \mathrm{H}, J=9 \mathrm{~Hz})$. Found, \%: C 76.67; H 3.91; N 8.64. $\mathrm{C}_{20} \mathrm{H}_{12} \mathrm{~N}_{2} \mathrm{O}_{2}$. Calculated, \%: C 76.91; H 3.87; N 8.97.

4,5-Bis(phenylsulfanyl)phthalonitrile (2). Yield: $1.4 \mathrm{~g}(83 \%)$ as a yellowish powder soluble in acetone, chloroform, DMF, DMSO. IR $v \mathrm{~cm}^{-1}: 2231(\mathrm{C} \equiv \mathrm{N}), 692(\mathrm{C}-\mathrm{S}-\mathrm{C}) .{ }^{1} \mathrm{H}$ NMR $\delta_{\mathrm{H}} \mathrm{ppm}$ : 7.59-7.57 m (4H), 7.56-7.54 m (4H), $7.33 \mathrm{t}(2 \mathrm{H}, J=8 \mathrm{~Hz}), 7.02$ s (2H). Found, \%: C 69.33; H 3.55; N 8.02; S 18.11. $\mathrm{C}_{20} \mathrm{H}_{12} \mathrm{~N}_{2} \mathrm{~S}_{2}$. Calculated, \%: C 69.74; H 3.51; N 8.13, S 18.62.

Condensation of 4,5-diphenoxyphthalonitrile (1) with tetrachlorophthalonitrile. To a refluxing solution of lithium hexan-1-olate in hexan-1-ol prepared by dissolving $0.1 \mathrm{~g}(14 \mathrm{mmol})$ lithium in $30 \mathrm{ml}$ of anhydrous hexan-1-ol, $0.31 \mathrm{~g}(1 \mathrm{mmol})$ of nitrile 1 , and $0.52 \mathrm{~g}(2 \mathrm{mmol})$ of tetrachlorophthalonitrile were added. After $3 \mathrm{~h}$ $20 \mathrm{ml}$ of the alcohol was distilled off. The reaction mixture was cooled and treated with $50 \mathrm{ml}$ of acetonitrile and $10 \mathrm{ml}$ of acetic acid, the precipitate formed was filtered, washed with $30 \mathrm{ml}$ of acetonitrile and dried. The residue was purified by chromatography on a column with Kieselgel 60 eluting with chloroform-ethanol 99:1. The mixture was thus separated into 3 zones containing phthalocyanines $\mathbf{3}, \mathbf{5}, \mathbf{7}$ correspondingly. The solvents were removed yielding:

2,3,9,10,16,17-Hexaphenoxy-22,23,24,25-tetrachlorophthalocyanine $(3)\left(A_{3} B\right)$. Yield: $40 \mathrm{mg}(10 \%)$ as a green powder highly soluble in benzene, chloroform while poorly soluble in acetonitrile and alcohols. UV-Vis (benzene) $\lambda_{\text {max }} \mathrm{nm}\left(A / A_{\max }\right): 716(1.00), 686$ (flat), 659 (0.52), 342 (0.73). $\mathrm{m} / \mathrm{z}$ (MALDI): $1202.2\left[\mathrm{~m}^{+}\right.$(100\%). ${ }^{1} \mathrm{H} \mathrm{NMR}\left(\mathrm{CDCl}_{3}\right) \delta_{\mathrm{H}}$ ppm: 7.75-7.10 m (36H), -7.02 wid.s. (2H). Found, \%: $\mathrm{C}$ 68.01; $\mathrm{H} 3.43 ; \mathrm{N}$ 8.93. $\mathrm{C}_{68} \mathrm{H}_{38} \mathrm{Cl}_{4} \mathrm{~N}_{8} \mathrm{O}_{6}$. Calculated, \%: C 67.78; H 3.18; N 9.30.

2,3,9,10-Tetraphenoxy-15,16,17,18,22,23,24,25-octachlorophthalocyanine (5) (AABB). Yield: $120 \mathrm{mg}(22 \%)$ of green powder highly soluble in benzene, chloroform, while poorly soluble in acetonitrile and alcohols. UV-Vis (benzene) $\lambda_{\max } \mathrm{nm}\left(A / A_{\max }\right)$ : 712 (1.00), 656 (0.77), 342 (0.86). $m / z$ (MALDI): $1155.1[M+\mathrm{H}]^{+}$ $(100 \%)$. ${ }^{1} \mathrm{H}$ NMR $\delta_{\text {н }}$ ppm: 8.20-7.15 m (24H). Found, \%: C 58.77; $\mathrm{H}$ 2.45; $\mathrm{N}$ 9.21. $\mathrm{C}_{56} \mathrm{H}_{26} \mathrm{Cl}_{8} \mathrm{~N}_{8} \mathrm{O}_{4}$. Calculated, \%: C 58.06; $\mathrm{H} 2.26 ; \mathrm{N}$ 9.67 .

2,3,16,17-Tetraphenoxy-8,9,10,11,22,23,24,25-octachlorophthalocyanine (7) (ABAB). Yield: $65 \mathrm{mg}(12 \%)$ of green powder highly soluble in benzene and chloroform, poorly soluble in acetonitrile and alcohols. UV-Vis (benzene) $\lambda_{\max } \mathrm{nm}\left(A / A_{\max }\right)$ :
699 (0.88), 644 (0.97), 337 (1.00). $m / z$ (MALDI): $1155.5[M+\mathrm{H}]^{+}$ (100\%). ${ }^{1} \mathrm{H}$ NMR $\delta_{\mathrm{H}}$ ppm: $8.33-7.10 \mathrm{~m}(24 \mathrm{H}),-6.88 \mathrm{br}(2 \mathrm{H})$. Found, \%: C 58.82; $\mathrm{H} 2.11 ; \mathrm{N} 9.10 . \mathrm{C}_{56} \mathrm{H}_{26} \mathrm{Cl}_{8} \mathrm{~N}_{8} \mathrm{O}_{4}$. Calculated, \%: C 58.06; H 2.26; N 9.67.

Condensation of 4,5-bis(phenylsulfanyl)phthalonitrile (2) with tetrachlorophthalonitrile. To a refluxing solution of lithium hexan-1-olate in hexan-1-ol prepared by dissolving $0.1 \mathrm{~g}$ (14 $\mathrm{mmol})$ lithium in $30 \mathrm{ml}$ of anhydrous hexan-1-ol, $0.34 \mathrm{~g}(1 \mathrm{mmol})$

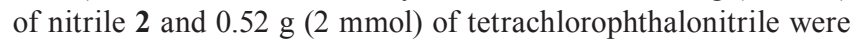
added. After $4 \mathrm{~h} 20 \mathrm{ml}$ of the alcohol was distilled off. The reaction mixture was cooled and treated with $50 \mathrm{ml}$ of acetonitrile and $10 \mathrm{ml}$ of acetic acid, the precipitate formed was filtered, washed with $30 \mathrm{ml}$ of acetonitrile and dried. The residue was purified by chromatography on a column with Kieselgel 60 eluting with chloroform-ethanol 95:5. The mixture was thus separated into 3 zones containing phthalocyanines $4,6,8$ correspondingly. The solvents were removed yielding:

2,3,9,10,16,17-Hexakis(phenylsulfanyl)-22,23,24,25-tetrachlorophthalocyanine (4) $\left(A_{3} B\right)$. Yield: $34 \mathrm{mg}(8 \%)$ of green powder highly soluble in benzene and chloroform, poorly soluble in acetonitrile and alcohols. UV-Vis (benzene) $\lambda_{\text {max }} \mathrm{nm}\left(A / A_{\max }\right): 726$ (0.97), 711 (1.00), 663 (0.70), 345 (0.76). $\mathrm{m} / z$ (MALDI): 1298.1 $[M]^{+}(100 \%) .{ }^{1} \mathrm{H}$ NMR $\delta_{\mathrm{H}} \mathrm{ppm}: 8.01-7.08 \mathrm{~m}(36 \mathrm{H})$. Found, \%: C 63.22; H 2.71; N 8.51; S 14.00. $\mathrm{C}_{68} \mathrm{H}_{38} \mathrm{Cl}_{4} \mathrm{~N}_{8} \mathrm{~S}_{6}$. Calculated, \%: C 62.77 ; H 2.94; N 8.61; S 14.78 .

2,3,9,10-Tetrakis(phenylsulfanyl)-15,16,17,18,22,23,24,25octachlorophthalocyanine (6) (AABB). Yield: $100 \mathrm{mg}$ (17\%) of green powder highly soluble in benzene and chloroform, poorly soluble in acetonitrile and alcohols. UV-Vis (benzene) $\lambda_{\max } \mathrm{nm}$ $\left(A / A_{\text {max }}\right): 710$ (0.82), 657 (0.51), 341 (1.00). m/z (MALDI): 1218.8 $[M+\mathrm{H}]^{+}(100 \%) .{ }^{1} \mathrm{H}$ NMR $\delta_{\mathrm{H}}$ ppm: 8.41-7.13 m (24H), -7.49 br (2H). Found, \%: C 55.82; $\mathrm{H} 2.33$; N 8.81; S 9.95. $\mathrm{C}_{56} \mathrm{H}_{26} \mathrm{Cl}_{8} \mathrm{~N}_{8} \mathrm{~S}_{4}$ Calculated, \%: C 55.01; H 2.14; N 9.16; S 10.49.

2,3,16,17-Tetrakis(phenylsulfanyl)-8,9,10,11,22,23,24,25octachlorophthalocyanine (8) (ABAB). Yield: $23 \mathrm{mg}$ (4\%) of green powder highly soluble in benzene and chloroform, poorly soluble in acetonitrile and alcohols. UV-Vis (benzene) $\lambda_{\max } \mathrm{nm}\left(A / A_{\max }\right)$ : 707 (0.89), 655 (1.00), 351 (0.94). $\mathrm{m} / z$ (MALDI): $1219.2[M+\mathrm{H}]^{+}$ (100\%). ${ }^{1} \mathrm{H}$ NMR $\delta_{\mathrm{H}}$ ppm: 8.40-7.10 m (24H). Found, \%: C 56.01; $\mathrm{H}$ 2.26; N 9.08; $\mathrm{S} 10.00 . \mathrm{C}_{56} \mathrm{H}_{26} \mathrm{Cl}_{8} \mathrm{~N}_{8} \mathrm{~S}_{4}$. Calculated, \%: C 55.01; $\mathrm{H}$ 2.14; N 9.16; S 10.49 .

\section{Results and Discussion}

The most common synthetic route to low-symmetry phthalocyanines is the cross-condensation of two differently substituted phthalonitriles (components A and B).$^{\left[{ }^{8,9]} \text { In the }\right.}$ current research we used 4,5-diphenoxyphthalonitrile $\mathbf{1}$ and 4,5-bis(phenylsulfanyl)phthalonitrile $\mathbf{2}$ as A-components.

In paper ${ }^{[7]}$ these compounds were obtained by reacting 4,5-dichlorophthalonitrile with phenol or thiophenol at $90{ }^{\circ} \mathrm{C}$ in DMSO in the presence of potassium carbonate, with subsequent dilution of the reaction mixture with water and extraction of the target nitriles with chloroform. In the current work this procedure (Scheme 1) was modified by replacing DMSO with DMF and increasing the reaction temperature to $110{ }^{\circ} \mathrm{C}$. Upon completion of the reaction the mixture was diluted with water, the formed precipitate filtered, washed with $\mathrm{KOH}$ solution and water to $\mathrm{pH} 7$ and dried. The extraction step was thus avoided. The yields of nitriles 1,2 were $83-85 \%$, which is close to the results reported earlier. ${ }^{[7]}$

Compounds 1, 2 are greyish and yellowish correspondingly, they are highly soluble in benzene, chloroform and 


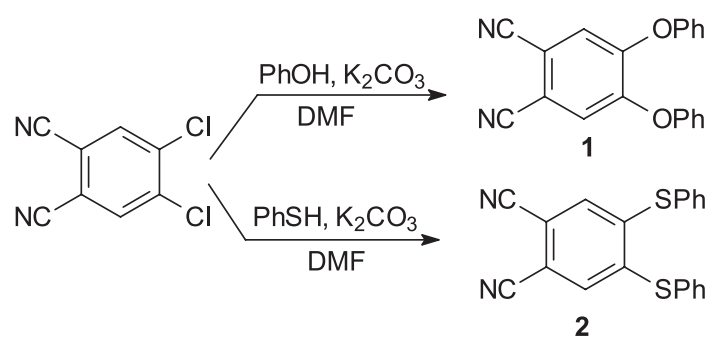

Scheme 1.

DMF, poorly soluble in alcohols. Their composition and structure were confirmed by elemental analysis, IR and ${ }^{1} \mathrm{H}$ NMR spectroscopy.

The bands in the IR spectra of the synthesized nitriles demonstrate the presence of nitrile groups (2226 and $\left.2231 \mathrm{~cm}^{-1}\right)$ as well as $\mathrm{C}-\mathrm{O}-\mathrm{C}\left(1248 \mathrm{~cm}^{-1}\right)$ and $\mathrm{C}-\mathrm{S}-\mathrm{C}$ bonds $\left(692 \mathrm{~cm}^{-1}\right)$.

${ }^{1} \mathrm{H}$ NMR spectral data for nitriles $\mathbf{1}$ and $\mathbf{2}$ are given in paper. ${ }^{[7]}$ The authors report the spectra of $\mathbf{1}$ in DMSO- $d_{6}$ to have four signals two of which are singlets at 7.68 and $7.22 \mathrm{ppm}$ with the other two being doublets at 7.42 and $7.30 \mathrm{ppm}$. It should be noted that no assignment of the signals had been performed.

In the current work the ${ }^{1} \mathrm{H}$ NMR spectra of compounds $\mathbf{1}$ and $\mathbf{2}$ were recorded in $\mathrm{CDCl}_{3}$. The spectrum of $\mathbf{1}$ is presented in Figure 1.

It also consists of four signals but their position and multiplicity are different. The most downfield signal is the triplet at $7.48 \mathrm{ppm}$ corresponding to four $m$-protons of the phenoxyl substituents, the triplet at $7.32 \mathrm{ppm}$ corresponds to two $p$-protons, the singlet at $7.19 \mathrm{ppm}$ - to two phthalonitrile residue protons and the most upfield signal is the doublet at $7.12-7.10 \mathrm{ppm}$ which relates to four $o$-protons of the phenoxyl groups. As for the ${ }^{1} \mathrm{H}$ NMR spectrum of nitrile 2 (Figure 2), in comparison to the spectrum recorded in DMSO- $d_{6},{ }^{[7]}$ the upfield signals are observed ranging $0.13-0.38 \mathrm{ppm}$.
Heating the 1:2 mixture of nitriles $\mathbf{1}$ or $\mathbf{2}$ with tetrachlorophthalonitrile in refluxing hexan-1-ol in the presence of lithium hexan-1-olate followed by treatment with acetic acid leads, as shown in Scheme 2, to the formation of phthalocyanine mixtures. Compounds of the $\mathrm{A}_{3} \mathrm{~B}(\mathbf{3}, \mathbf{4}), \mathrm{AABB}(\mathbf{5}$, 6) and $\mathrm{ABAB}(7,8)$ types were isolated from the mixtures by column chromatography.

Under the reaction conditions phthalocyanines of the $\mathrm{A}_{4}$ type are formed only in trace amounts, while the $\mathrm{AB}_{3}$ and $\mathrm{B}_{4}$ types have very limited solubility and chromatographic mobility and thus cannot be isolated by chromatography.

Phthalocyanines 3-8 were obtained as green solids. Their composition and structure were confirmed by elemental analysis, MALDI-TOF mass spectrometry, ${ }^{1} \mathrm{H}$ NMR and electronic absorption spectra.

The mass spectra of compounds 3, 4 (Figure 3) show strong molecular peaks with $\mathrm{m} / \mathrm{z} 1202.2$ and 1298.1 correspondingly. Beside that for phthalocyanine 3 weak signals with $m / z 1110.3[M-\mathrm{OPh}+\mathrm{H}]^{+}$and $832.6[M-4 \mathrm{OPh}+2 \mathrm{H}]^{+}$are observed, while for compound 4 - signals with $m / z 1081.4$ $[M-2 \mathrm{SPh}+\mathrm{H}]^{+}$and $862.8[M-4 \mathrm{SPh}+\mathrm{H}]^{+}$.

The mass spectra of phthalocyanines 5-8 also show molecular ions as the major peaks, the fragmentation is insignificant and manifests in elimination of several phenoxyl or phenylsulfanyl fragments.

Due to their structure, phthalocyanines 3-8, are strongly susceptible to form aggregates in solutions. Therefore their ${ }^{1} \mathrm{H} \mathrm{NMR}$ spectra in $\mathrm{CDCl}_{3}$ have very poor resolution. ${ }^{1} \mathrm{H}$ NMR spectrum of compound $\mathbf{3}$ is demonstrated in Figure 4.

It consists of one wide multiplet in the range of 7.75-7.10 ppm, in which the resonance of six isoindole protons, $18 \mathrm{~m}$ and $p$-protons and $12 o$-protons of the phenoxyl substituents can be outlined. The ${ }^{1} \mathrm{H}$ NMR spectra of phthalocyanines 4-8 are alike compared to 3 and neither changing the concentration in the range $10^{-3}-10^{-5} \mathrm{~mol} / \mathrm{L}$ nor addition of trifluoroacetic acid (to obtain protonated forms of the phthalocyanines) did not afford a higher spectral resolution. The signals of the endocyclic protons in the ${ }^{1} \mathrm{H}$ NMR spectra are either not

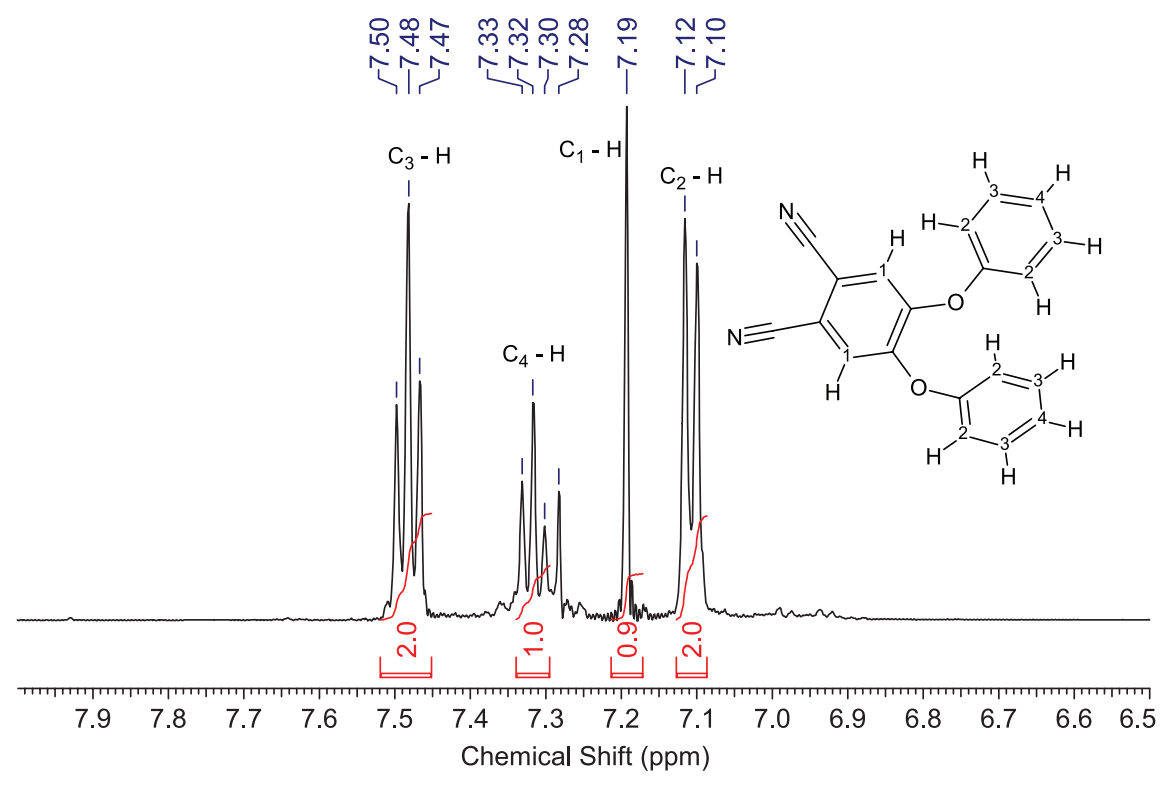

Figure 1. ${ }^{1} \mathrm{H}$ NMR spectrum of 4,5-diphenoxyphthalonitrile 1 in $\mathrm{CDCl}_{3}$. 
N. E. Galanin et al.

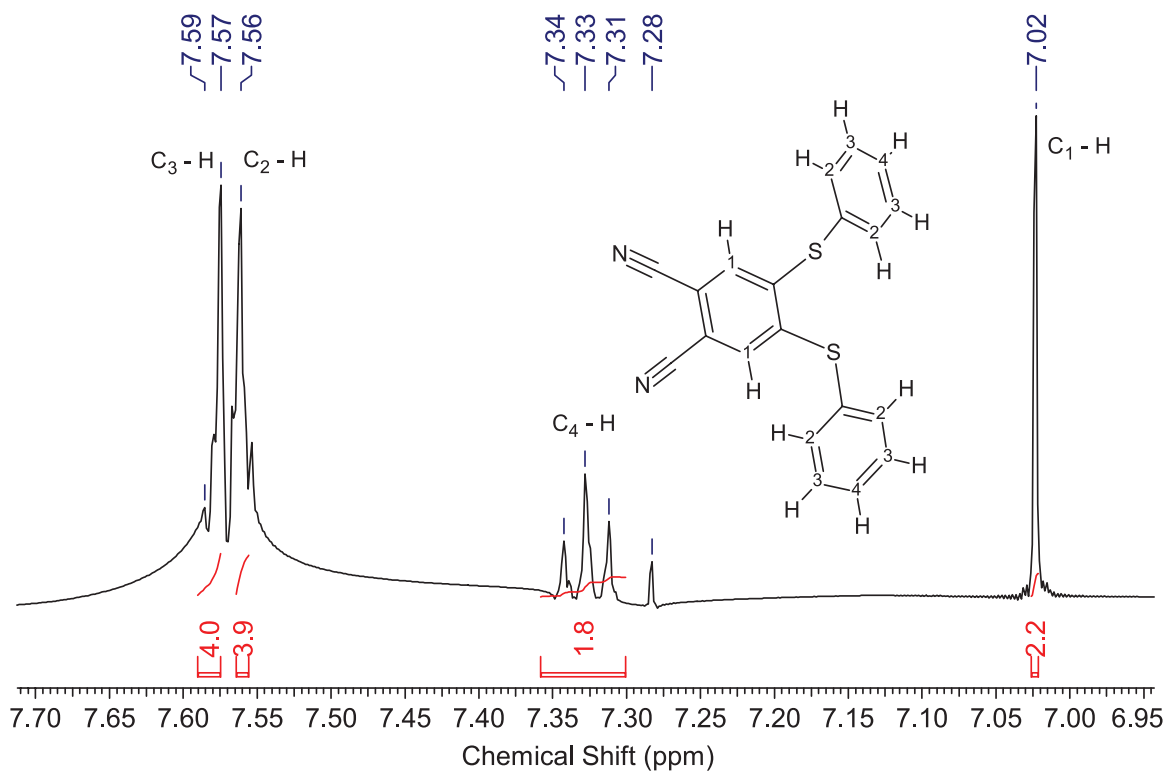

Figure 2. ${ }^{1} \mathrm{H}$ NMR spectrum of 4,5-bis(phenylsulfanyl)phthalonitrile 2 in $\mathrm{CDCl}_{3}$.

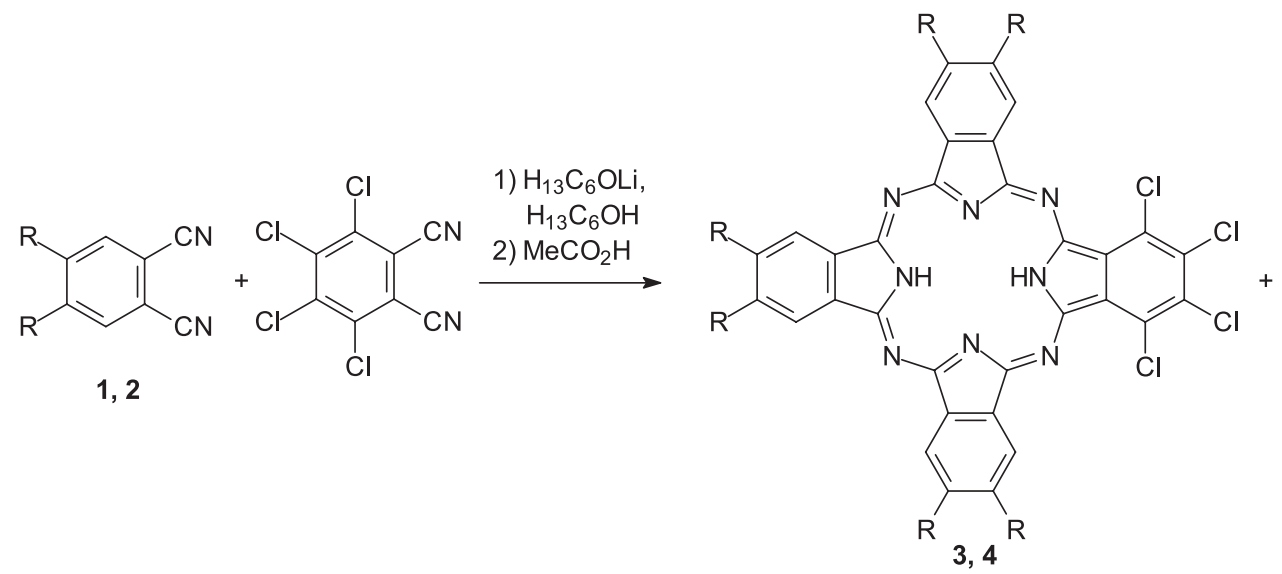

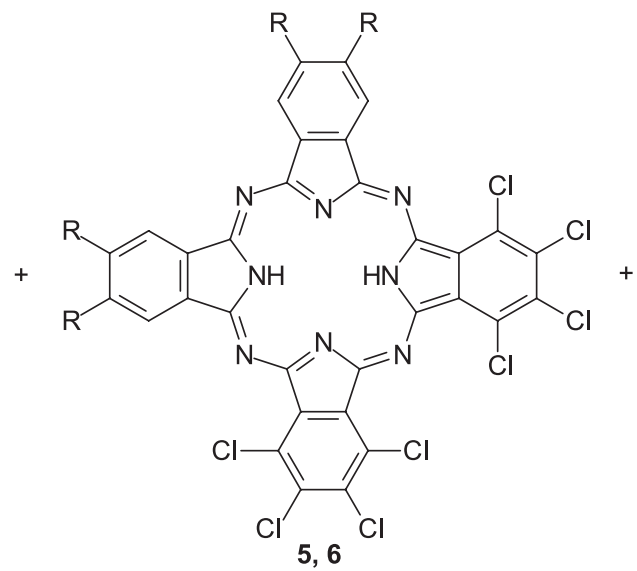

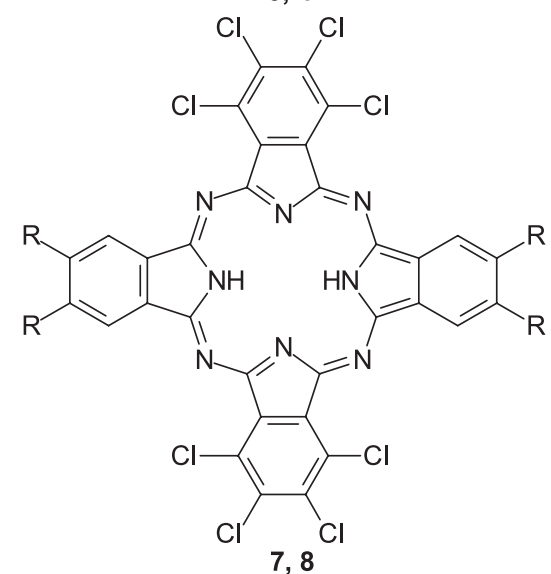

$\mathrm{R}=\mathrm{PhO}(1,3,5,7) ; \mathrm{R}=\mathrm{PhS}(2,4,6,8)$

Scheme 2.

detected or manifest as very wide singlets in the area $-6--8$ $\mathrm{ppm}$, which confirms the conclusion of strong aggregation of phthalocyanines in low-polarity solvents. Such upfield shifts of the endocycloc protons had been noted earlier in a study of NMR spectra of alcoxy substituted phthalocyanine aggregates. ${ }^{[10]}$
The electronic absorption spectra of phthalocyanines 3, 5, and $\mathbf{7}$ are shown in Figure 5.

In the spectrum of compound 3 (Figure 5, I) the $Q$-band is split into two components with maxima at 716 and $659 \mathrm{~nm}$ and an inflexion at $689 \mathrm{~nm}$. Such $Q$-band splitting is typical for low-symmetry phthalocyanines of the $\mathrm{A}_{3} \mathrm{~B}$ type ${ }^{[11]}$ The 

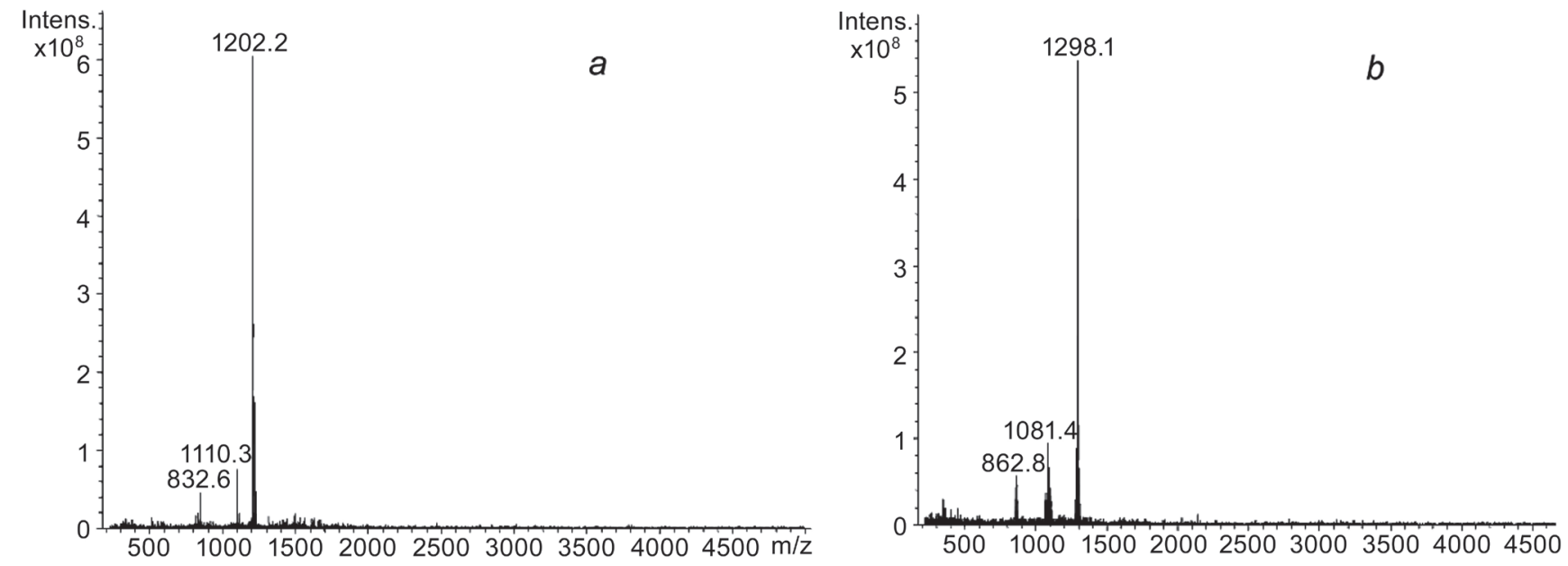

Figure 3. Mass spectra (MALDI-TOF): $a$ - compound 3, $b$ - compound 4.

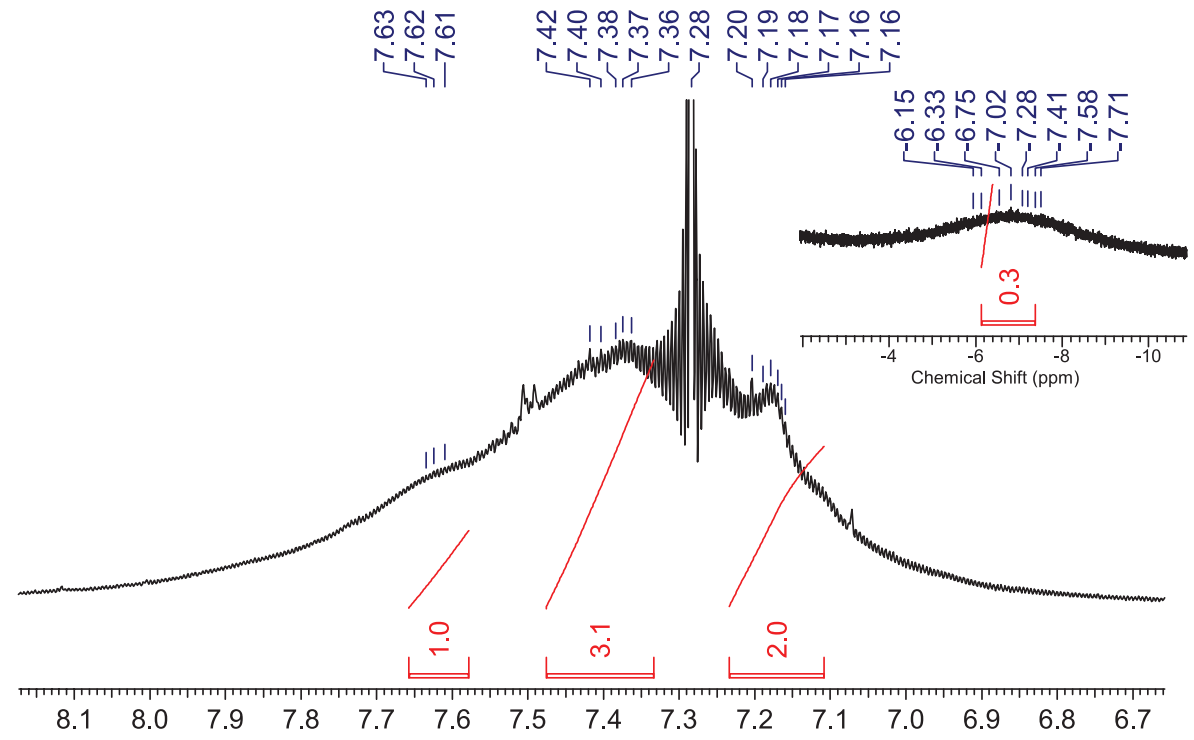

Figure 4. ${ }^{1} \mathrm{H}$ NMR spectrum of phthalocyanine 3 in $\mathrm{CDCl}_{3}$.

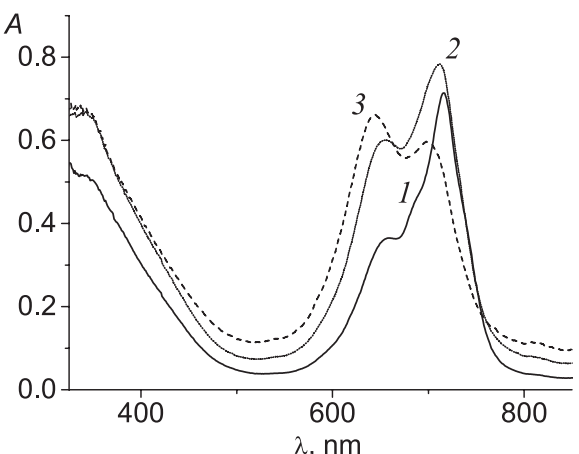

Figure 5. Electronic absorption spectra in benzene. 1 - compound 3, 2 - compound 5,3-compound 7 .

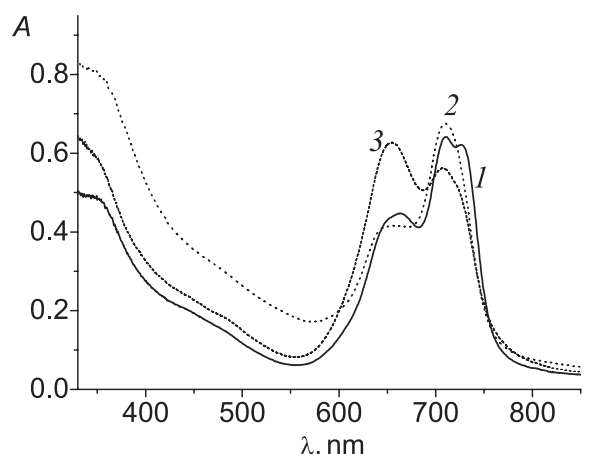

Figure 6. Electronic absorption spectra recorded in benzene. 1 - compound 4, 2 - compound $\mathbf{6}, 3$ - compound 8 . 
spectra of compounds 5, 7 (Figure 5, 2, 3) turn to be twobanded in the longwave region, while for the spectrum of 5 the longwave $Q_{1}$ band is more intensive, in the spectrum of 7 it is the shortwave $Q_{2}$ band. The $B$ bands maxima positions have little dependence on the number and position of the substituents.

Figure 6 presents electronic absorption spectra of phthalocyanines $4,6,8$.

In the spectrum of phthalocyanine 4 (Figure 6,1 ) the $Q$-band splitting is more pronounced than the one of compound 3, with three components at 726, 711 and $663 \mathrm{~nm}$. A slight $(4-10 \mathrm{~nm})$ bathochromic shift of the maxima is attributed to increased electron donating effect of the phenylsulfanyl fragments compared to the phenoxyl ones. The pattern of the spectra of $\mathbf{6 , 8}$ is close to those of phthalocyanines $\mathbf{5}$, 7 , with only a slight bathochromic shift of the maxima of the absorption bands. Furthermore, in the $450-550 \mathrm{~nm}$ region of the spectra of the phenylsulfanyl substituted phthalocyanines, wide low intensity bands manifest, caused by $n-\pi$ transitions involving non-bonding orbitals of sulfur of the phenylsulfanyl substituents.

Significant $Q$-band splitting exhibited by compounds 3-8 (50-60 $\mathrm{nm})$ allows to suggest that the longwave $Q_{1}$ bands refer to the absorption of monomeric forms of phthalocyanines, while the shortwave $Q_{2}$-bands - to aggregated forms. ${ }^{\text {[12] }}$ To prove this suggestion we studied the dependency of the intensity ratio of $Q_{2}$ and $Q_{1}$ bands on the concentration of the dissolved phthalocyanines. Figure 7 demonstrates such a dependency for compound 7.

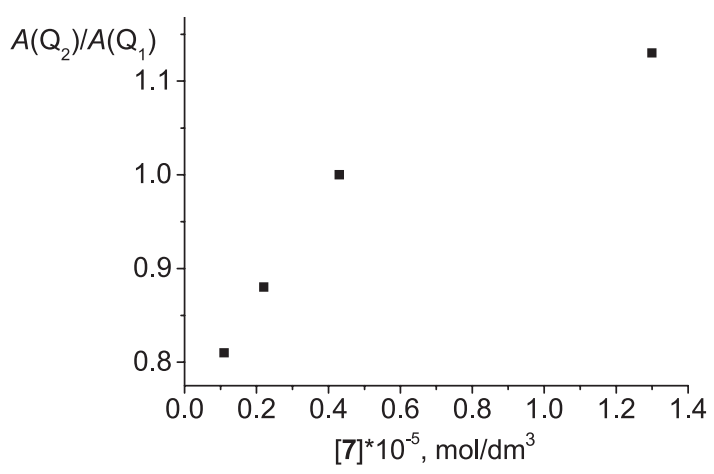

Figure 7. Dependency of $A\left(Q_{2}\right) / A\left(Q_{1}\right)$ ratio on phthalocyanine 7 concentration in benzene.

As the shortwave component $Q_{2}$ intensity is increased with increasing concentration of 7 , it testifies that this spectrum component actually does characterize the absorption of the aggregated phthalocyanine form, while the nonlinearity of this increase can be explained by formation of aggregates of a higher order than just dimers. A similar pattern is typical for other synthesized compounds.

It also should be noted that the spectral pattern of compounds 3-8 changes extremely insignificantly in a number of different solvents: benzene, THF, pyridine and dichloromethane, i.e. solvents with different polarity and coordinating ability, which demonstrates high stability of the aggregates.

In papers ${ }^{[13,14]}$ spectral properties of symmetric phthalocyanines metal complexes were studied, where the ligands had two phenoxyl or phenylsulfanyl groups correspondingly (positions 4, 5) and two chlorine atoms each (positions 3,6 ) in every benzene rings. It was demonstrated that such phthalocyanines do not tend to aggregate to a significant degree. Thus, the reason of a high degree of aggregation of compounds $\mathbf{3 - 8}$ in solutions is their significant dipole moments (3.3-6.5 D, computed by the AM-1 method) which are attributed to low symmetry.

\section{Conclusion}

Novel low-symmetry phenoxy(chloro)- and phenylsulfanyl(chloro)substituted phthalocyanines of the $\mathrm{A}_{3} \mathrm{~B}$, $A A B B$ and $A B A B$ types were synthesized. Spectral parameters of the obtained compounds were studied. Strong degree of aggregation in solutions was demonstrated on the basis of electronic absorption and ${ }^{1} \mathrm{H}$ NMR spectroscopic data.

Acknowledgements. The current research was conducted with the support of the Russian Foundation for Basic Research, project 14-23-00204.

\section{References}

1. de la Torre G., Torres T. J. Porphyrins Phthalocyanines 1997, $1,221-227$.

2. Lawrence D.S., Whitten D.G. J. Chem. Soc. 1996, 64, 923935.

3. Sastre A., Del Rey B., Torres T. J. Org. Chem. 1996, 61, 85918597.

4. de la Escosura A., Martinez-Diaz V.M., Thordarson P., Rowan A.E., Nolte R.J.M., Torres T. J. Am. Chem. Soc. 2003, 125, 12300-12308.

5. Usol'tseva N., Bykova V., Ananjeva G., Zharnikova N., Kudrik E. Mol. Cryst. Liq. Cryst. 2004, 411, 329-336.

6. Ma L., Zhang Y., Ping Yuan. Optics Express 2010, 18, 1766617671.

7. Tau P., Nyokong T. J. Porphyrins Phthalocyanines 2006, 10, 1040-1048.

8. Korelchuk M.V., Galanin N.E., Shaposhnikov G.P. Macroheterocycles 2013, 6, 268-273 (in Russ.).

9. Martynov A.G., Panova M.V., Gorbunova Y.G., Tsivadze A.Yu. Macroheterocycles 2014, 7, 47-54.

10. Marcuccio S.M., Svirskaya P.I., Greenberg S., Lever A.B.P., Leznoff C.C., Tomer K.B. Can. J. Chem. 1985, 63, 3057-3069.

11. Kudrik E.V., Bauer E., Ercolani C., Chiesi-Villa A., Rizzoli C., Gaberkorn A., Stuzhin P.A. Mendeleev Commun. 2001, 2, 45-47.

12. Maizlish V.E., Shirokov A.V., Kudrik E.V., Shaposhnikov G.P. Russ. J. Gen. Chem. 2002, 72, 1640-1644.

13. Volkov K.A., Avramenko G.V., Negrimovskii V.M., Luk'yanets E.A. Russ. J. Gen. Chem. 2007, 77, 1126-1133.

14. Volkov K.A., Avramenko G.V., Negrimovskii V.M., Luk'yanets E.A. Russ. J. Gen. Chem. 2007, 77, 1108-1116. 